\title{
Thermochemistry of Acrylamide Polymerization: An Illustration of Auto-acceleration and Gel Effect
}

\author{
Nedal Y. Abu-Thabit* \\ Department of Chemical and Process Engineering Technology, Jubail Industrial College, Jubail Industrial City 31961, Saudi Arabia \\ *Corresponding author: abuthabit_nidal@yahoo.com
}

\begin{abstract}
Addition polymerization of alkenes is an exothermic process due to the relief of the bond strain from C-C double bonds ( $\pi$ bonds) in the monomer molecules. Control of exothermic reactions is crucial for preventing runaway reactions/explosions in the industrial setting. This experiment was designed for undergraduate students to demonstrate the exothermic nature of addition (chain-growth) polymerization and to estimate the enthalpy of polymerization using adiabatic calorimetry technique. Acrylamide (AAM) was polymerized using ammonium persulfate (APS) and Tetramethylethylenediamine (TMEDA) as redox initiators at room temperature. The concentration of AAM monomer was varied in the range of 5-25 wt. \%, and the heat of polymerization was calculated from the recorded temperature rise $(\Delta \mathrm{T})$. The enthalpy of AAM polymerization $(\Delta \mathrm{Hp})$ was estimated to $\mathrm{be} \approx 16.5-19 \mathrm{kcal} / \mathrm{mole}$, depending on the monomer concentration. Enthalpy of polymerization was increased with increasing the monomer concentration due the auto-acceleration effect, which was clearly observed for solutions with AAM concentrations of $\geq 20 \mathrm{wt}$. \%. The auto-acceleration phenomenon was identified from the fast and non-linear increase in the rate of temperature rise which reached a maximum of $\left(0.5^{\circ} \mathrm{C} / \mathrm{s}\right)$ for solutions with AAM of 25 wt. \%. For AAM concentrations of $\geq 20$ wt. \%, the auto-acceleration was accompanied by the polymer gelation (gel effect) due to the formation of the high molecular weight polyacrylamides.
\end{abstract}

Keywords: polymer chemistry, polymerization, enthalpy of polymerization, redox polymerization, polyacrylamide, gel effect, auto-acceleration, norrish-smith effect, runaway reaction, solution polymerization

Cite This Article: Nedal Y. Abu-Thabit, “Thermochemistry of Acrylamide Polymerization: An Illustration of Auto-acceleration and Gel Effect.” World Journal of Chemical Education, vol. 5, no. 3 (2017): 94-101. doi: 10.12691/wjce-5-3-3.

\section{Introduction}

Addition polymerization of polyolefins represents one of the major industrial processes with annual polymer production of almost 180 million ton and around \$200 billion profits value [1]. Addition (chain-growth) polymerization is characterized by its exothermic nature with enthalpy of polymerization in the range of $15-20 \mathrm{kcal} / \mathrm{mole}$ depending on the monomer structure and the employed polymerization conditions [2,3]. Addition polymerization is driven by enthalpy change due to the relief of bond strain from the strained C-C double bonds ( $\pi$ bonds), which results in releasing high amounts of heat from the exothermic polymerization. Hence, one of the most important aspects of olefin polymerizations is the control of reactor temperature to avoid heat transfer problems resulted from the highly exothermic alkene polymerization. Estimation of the polymerization enthalpy is crucial and very useful for optimization of heat transfer as well as scale-up of polymerization reactions.

\subsection{Auto-acceleration and Gel Effect}

The rapid and uncontrolled increase in temperature, which is referred to as "auto-acceleration", was first noticed by Norrish during the bulk polymerization of methyl methacrylate [4]. Also this effect is known as Norrish-Smith effect [5], Trommsdroff effect [6], Norrish-Trommsdroff effect [7] and gel effect [7,8].

The main cause of the auto-acceleration is the high viscosity of the reaction medium due to the very high molecular weight. The high viscosity hinders the segmental motion of the polymer chains, and consequently, the termination stops as the chains are unable to combine/ couple for termination. In such situation, the diffusion is termed as "reaction diffusion" [2]. In comparison, the diffusion of small monomer molecules is not affected and, hence, the propagation reaction continues. The kinetics rate law for the free radical polymerization is shown in equation 1 :

$$
R_{p}=k_{p}\left(\frac{f k_{d}}{k_{t}}\right)^{1 / 2}[I]^{1 / 2}[M]
$$

Where:

$\mathrm{R}_{\mathrm{p}}=$ Rate of polymerization

$k_{p}=$ Rate constant for propagation

$\mathrm{k}_{\mathrm{d}}=$ Rate constant for dissociation

$\mathrm{k}_{\mathrm{t}}=$ Rate constant for termination

$\mathrm{f}=$ dissociation efficiency of the initiator

[I] = concentration of the initiator

$[\mathrm{M}]=$ concentration of the monomer. 
Based on the above discussion, the auto-acceleration effect/ gel effect can be summarized as following:

1) Termination stops ( $\left.k_{t} \approx 0\right)$, (almost no termination), because of high viscosity which limits the chains mobility and diffusion.

2) High propagation reaction rates ( $k_{p}$ is not affected) because monomer size is small, even though high viscosity (still can easily diffuses). From equation 1 :

$$
R_{p} \propto k_{p}\left(\frac{1}{k_{t}}\right)^{1 / 2}
$$

Hence, $R_{p} \rightarrow \infty$ (Actually $R_{p}$ increases by $>100$ folds)

3) Auto-acceleration by exothermic propagation reaction. This will lead to loss of heat control (runaway) and possible explosion.

4) The obtained polymer has extraordinary high molecular weight polymer and it looks like a gel, which is of less practical use to its limited dispersibility/ solubility. Regardless, this kind of reactions can be utilized for gel casting process $[9,10]$.

\subsection{Bulk Polymerization}

In bulk polymerization, the initiator is mixed with pure monomer. The absence of solvent makes it too difficult to control the temperature and viscosity of the polymerization medium due to high amount of evolved heat and high molecular weight caused by the accelerated exothermic polymerization reaction. This the same reason for adding small amounts (ppm level) of inhibitors (radical scavenger, e.g. hydroquinone) to commercial monomers during shipping or storage. Although bulk polymerization produces high purity polymers with minimal contaminations (e.g. initiator, solvent, emulsifier or stabilizers), the auto-acceleration leads to a broader molecular weight distribution due to chain transfer to polymer; and generation of local hot spots with degradation/ discoloration of the produced polymer [2]. To overcome the limitations of bulk polymerization, solvent can be introduced to the polymerization system by using solution, suspension or emulsion polymerization techniques [11].

\subsection{Hazardous of Exothermic Polymerization Scale-Up}

Since the majority of industrial processes are exothermic, it is important for chemists and chemical engineers to understand and become familiar with heat generation and heat removal for exothermic reactions [12]. Recently, the decomposition reaction of hydrogen peroxide catalyzed by potassium iodide (elephant toothpaste demo) has been utilized as an experiment for demonstrating the hazards of exothermic reaction scale-up [12]. The experiment was carried out with same concentrations, but with different scales, using round bottom flasks with different volumes in the range of 100-1000 mL. The exothermic reaction was cooled by using an ice bath with agitation. For $100 \mathrm{~mL}$ reaction, the temperature was controlled and showed a minimal change. However, when the reaction was scaled-up into $1000 \mathrm{~mL}$, the reaction showed violent and uncontrolled thermal runaway behavior. Heat removal from the $1000 \mathrm{~mL}$ flask is not as effective as that in case of $100 \mathrm{~mL}$ flask. It was found that the heat transfer coefficient for the $1000 \mathrm{~mL}$ flask is lower than that for the $100 \mathrm{~mL}$ flask by $\approx 32 \%$ due to the lower ratio of the (surface area/ volume) for the bigger flask.

The auto-acceleration effect will be more serious during the scale-up of polymerization process. The rate of a chemical reaction is fixed at any given temperature but temperature may be influenced by mass transfer and heat transfer, which are in turn affected by the size and design of the reactor [13]. The main factors affecting the removal of heat are the size of the reactor, stirring and cooling [13]. Heat production is affected by the concentration of reactants, concentration of catalysts and starting temperature [13]. During the scale up process, it is important to consider the surface area of the reactor and not the volume. The obvious reason is that the heat produced increases with the volume of the reaction mixture, whereas the heat removed depends on the surface area available for heat transfer. As the ratio of volume to surface area increases, the cooling process may become inadequate leading to runaway reactions. Hence, the first and most critical step in the scale-up procedure is to undertake a risk assessment of the proposed chemical process with a proper study for the thermochemistry of the proposed reaction [13].

In the industrial setting, failure or ineffective heat removal can lead to catastrophic events due to the rapid increase in reactor temperature, rapid buildup of pressure inside the reactor and, consequently, reactor explosion or runaway polymerization reactions. As an example, on May 18, 2001, a destructive fire and explosion accident occurred in an acrylic resin manufacturing plant located in the northern part of Taiwan [14]. More than 100 people were injured and totally 46 plants including 16 high-tech companies nearby were severely damaged [14]. The explosion was attributed to a runaway polymerization reaction of a 6 ton reactor. It was estimated that the reactor temperature increased from $\left.60^{\circ} \mathrm{C}\right)$ to $\approx 170-210^{\circ} \mathrm{C}(\Delta \mathrm{T} \approx$ $110-130^{\circ} \mathrm{C}$ ), with the maximum temperature rising of $192^{\circ} \mathrm{C} / \mathrm{min}$. Therefore, runaway free-radical polymerization reactions are not practiced in the industrial settings because of their potentially disastrous consequences [2].

Inhibitors are added to pure monomers intended for storage or shipping due to the possible explosive runaway polymerizations that could happen during storage of monomers, especially in the presence of heat source (e.g. hot summer season), or when stored for long periods $[15,16]$. In the absence of inhibitors, this kind of bulk auto-polymerization is spontaneous, even at ambient room temperature, due to the auto-acceleration nature of free radical polymerization.

\subsection{Solution Polymerization of Acrylamide (AAM)}

Water soluble polymers such as polyacrylamide are usually produced by solution polymerization using water as a solvent. Polyacrylamide is used as a flocculant for waste water treatment, paper sizing and paper coating in paper mills and for enhanced oil recovery (polymer flooding). In molecular biology laboratory, polyacrylamide 
gels are used for nucleic acids (DNA) sequence analysis and protein identification by gel electrophoresis. Acrylamide can be polymerized by using water-soluble initiators such as ammonium persulfate, potassium persulfate or sodium persulfate. Persulfate initiators $\left(\mathrm{S}_{2} \mathrm{O}_{8}{ }^{2}-\right)$ dissociate at $60^{\circ} \mathrm{C}$ to produce the radical sulfate anions $\left(\mathrm{SO}_{4}^{-{ }^{-}}\right)$initiating species. However, the polymerization can be carried out using redox initiators such as persulfate/ tertiary amines, persulfate/ $\mathrm{Fe}^{2+}$ redox systems [17].

The polymerization of acrylamide is highly exothermic with reported enthalpy of polymerization $(\Delta \mathrm{Hp})$ of $\approx 17.0$ $20 \mathrm{Kcal} /$ mole $[18,19,20]$. The concentration of acrylamide monomer is limited by the high polymerization enthalpy to avoid situations of uncontrolled viscosity and temperature which will result in gelation, limited polymer solubility, lower conversions, lower molecular weights or runaway polymerization reactions [21,22]. In this experiment, acrylamide is polymerized by solution polymerization using the redox pair, ammonium persulfate (APS) and Tetramethylethylenediamine (TMEDA), as redox initiator, Figure 1. Enthalpy of polymerization can be calculated from the raised temperature, mass of solution and specific heat of solution, Equation (2). Since the used solutions are not dilute, the heat capacity of water cannot be used to represent the solution (monomer + polymer + water). Instead, the specific heat capacities for water and monomer/polymer are used as shown in Equation (3).

$$
\Delta \mathbf{H}_{\mathbf{p}}(\mathbf{J})=\mathbf{m x S x} \Delta \mathbf{T}
$$

Where, $\mathbf{m}=$ total mass of solution, $(\mathrm{g})$

$\mathrm{S}=$ specific heat of solution $\left(\mathrm{J} \mathrm{g}^{-1} \mathrm{~K}^{-1}\right)$

$\Delta \mathbf{T}=$ rise in temperature, $(\mathrm{K})$

Specific heat capacity for water $\left(\mathrm{S}_{\text {water }}\right)=4.2 \mathrm{~J} \mathrm{~g}^{-1} \mathrm{~K}^{-1}$

Specific heat capacity for monomer/polymer solutions $\left(\mathrm{S}_{\text {Monomer }}\right)=2.1 \mathrm{~J} \mathrm{~g}^{-1} \mathrm{~K}^{-1}$

$$
\begin{aligned}
\Delta \mathbf{H}_{\mathbf{p}}(\mathbf{J})= & {\left[\begin{array}{l}
\left(\mathbf{m}_{\text {water }} \mathbf{x} \mathbf{S}_{\text {water }}\right) \\
+\left(\mathbf{m}_{\text {monomer }} \mathbf{x} \mathbf{S}_{\text {monomer }}\right)
\end{array}\right] \mathbf{x} \Delta \mathbf{T} } \\
& \Delta H\left(\frac{J}{\text { mole }}\right)=\frac{\Delta H(J)}{n}
\end{aligned}
$$

where,

$$
\begin{aligned}
& n=\text { moles of acrylamide monomer } \\
& n=\frac{\text { mass of acrylamide }(\mathrm{g})}{71\left(\frac{\mathrm{g}}{\text { mole }}\right)} .
\end{aligned}
$$

\section{Educational Objectives}

The objectives of this experiment are summarized below:

a) To introduce room temperature redox polymerization system

b) To visual and demonstrate the auto-acceleration effect and gel effect.

c) To realize the possibility of hazardous runaway polymerization reactions during bulk polymerization or solution polymerization with high concentrations of monomer.

d) To estimate the enthalpy of polymerization $(\Delta \mathrm{Hp})$ for polyacrylamide

e) To understand the importance of temperature control inside the polymerization reactors during the scale-up procedure.

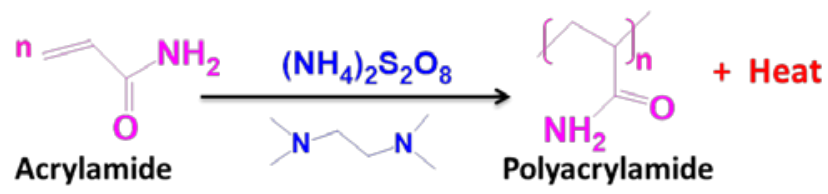

Figure 1. Redox polymerization of acrylamide monomer

\section{Experimental Overview}

This experiment was designed as a part of industrial polymerization course for polymer engineering technology undergraduates during the third semester and after completion of the prerequisite course "polymer chemistry”. In theory classes, students were introduced to the following concepts: enthalpy of polymerization, calorimetry, gel effect and auto-acceleration. The experiment was implemented during the last five academic semesters with an average number of 25 students/ semester. The experiment was designed to be completed during three laboratory sessions ( $\approx 3$ hours) as proposed in Table 1.

Figure 2 shows the digital image for the reaction setup which consists of a stirrer equipped with temperature monitoring probe. It is important to use large magnetic stir bars for effective stirring and monitoring the changes in solution viscosity. Each group will carry out one polymerization using different initial monomer

\begin{tabular}{|c|c|}
\hline Session/ Task Description & Time, Min \\
\hline $\begin{array}{l}\text { Session } 1 \\
\text { Describing the objectives of the experiment; recall enthalpy of polymerization, calorimetry and solution polymerization. }\end{array}$ & 20 \\
\hline $\begin{array}{l}\text { Describing the calorimeter setup; Describing the experimental procedure, assigning students into } 4 \text { groups, and } \\
\text { distributing the tasks among the group members }\end{array}$ & 15 \\
\hline $\begin{array}{l}\text { Reagent and setup preparation: weighing the monomer, initiator, preparing monomer and initiator solutions and prepare } \\
\text { reaction setups }\end{array}$ & 15 \\
\hline $\begin{array}{l}\text { Session } 2 \\
\text { Undertaking the polymerization reactions, data recording and observations }\end{array}$ & 60 \\
\hline $\begin{array}{l}\text { Session } 3 \\
\text { Preparing graphs; calculation of polymerization enthalpy }(\Delta \mathrm{Hp}) \text {; comparing the results among the four groups; } \\
\text { interpretation of the obtained results/ observations; conclusions. }\end{array}$ & 60 \\
\hline Total time for all tasks & 170 \\
\hline
\end{tabular}
concentration as illustrated in Table 2. Each group is requested to record the reaction temperature every minute along with any other observations.

Table 1. Overview of the Major Experimental Task 
Table 2. Polymerization recipes

\begin{tabular}{|c|c|c|c|c|}
\hline Group No. & $\begin{array}{c}\text { Mass of Acrylamide Monomer } \\
\text { (g) }\end{array}$ & $\begin{array}{c}\text { Acrylamide Content } \\
\text { (Wt. } \mathbf{\%})\end{array}$ & $\begin{array}{c}\text { Mass of APS Initiator } \\
\text { (g) }\end{array}$ & $\begin{array}{c}\text { Volume of TMEDA Catalyst }^{4} \\
(\mathbf{m L})\end{array}$ \\
\hline 1 & 5.2 & 5 & 0.1500 & 0.25 \\
\hline 2 & 11.1 & 10 & 0.1500 & 0.1500 \\
\hline 3 & 25.0 & 20 & 0.25 \\
\hline 4 & 33.4 & 25 & 0.1500 & 0.25 \\
\hline
\end{tabular}

${ }^{\mathbf{1}}$ Monomer solution is prepared by dissolving the required mass of monomer in $100 \mathrm{~mL}$ distilled water

${ }^{2}$ Students are required to record the exact mass of acrylamide monomer for calculation part

${ }^{3} \mathrm{~A}$ Digital balance with accuracy of $\pm 0.0001 \mathrm{~g}$ is used for weighing the initiator. Alternatively, $1.5 \mathrm{~mL}$ of freshly prepared $10 \%$ (w/w) APS solution can be added.

${ }^{4} \mathrm{~A} 1 \mathrm{~mL}$ dropper can be used to measure $0.25 \mathrm{~mL}$; or a micropipette can be used to measure $250 \mu \mathrm{L}$

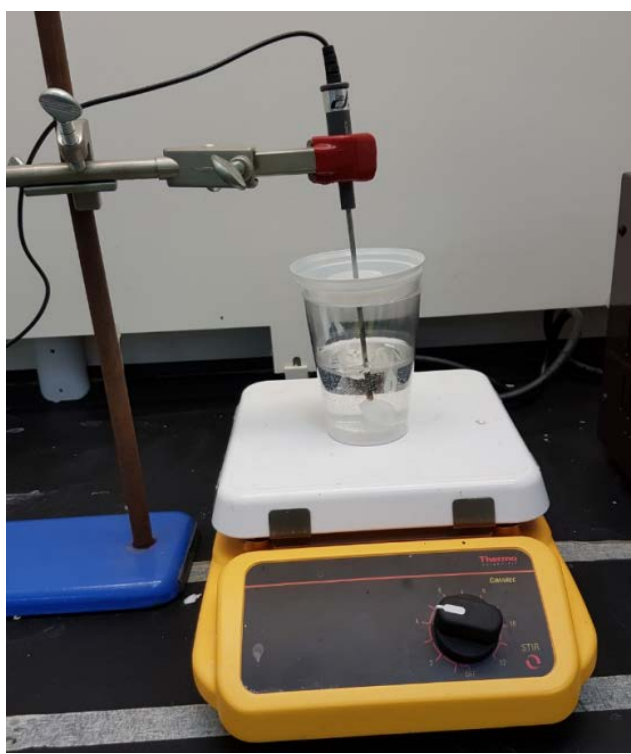

Figure 2. Experimental setup for polymerization reactions

\subsection{Experimental Procedure}

The brief experimental procedure is as following: the required mass of acrylamide monomer was weighed directly inside the cup calorimeter, followed by addition of $100 \mathrm{~mL}$ distilled water. The dissolution process is fast and endothermic. When the mass of monomer is in the range of $10-35 \mathrm{~g}$, solution temperature will be lowered by $5-15^{\circ} \mathrm{C}$, which will increase the induction period due to the lower initiation rates at lower temperatures. It is advised to use the hot water as heating aid to bring the monomer solutions to about the same room temperature for obtaining comparable results among different groups. After that, APS initiator $(0.150 \mathrm{~g})$ was added and the monomer solution was stirred for 2-3 minutes. Finally, TMEDA catalyst $(250 \mu \mathrm{L})$ was added, and the calorimeter was covered with a polystyrene lid. The temperature was recorded every one minute until a maximum temperature was reached. Polymerization solutions shall be discarded in a closed container labeled with "polyacrylamide/ acrylamide" for waste incineration; gelled polyacrylamide samples shall be stored in labeled plastic bags for waste incineration.

\subsection{Hazardous}

Although it was discovered in 2002 that acrylamide is present in roasted/heated starchy foods such as potato chips (potato crisps) and French fries (chips), acrylamide is suspected to be carcinogenic [23,24]. Acrylamide is toxic if swallowed and may cause irritation by skin contact. The product (polyacrylamide) is slightly benign. However, polymerized acrylamide solutions/ gels contain small/ residual amounts of unreacted acrylamide monomer. They should be collected and labeled separately for waste incineration. Ammonium persulfate is a strong oxidizing agent and skin irritant. N,N,N',N'-Tetramethylethylenediamine (TMEDA) is extremely hazardous in case of eye/ skin contact (irritant), of ingestion. Students must wear proper personal protective equipment (lab coat, eye goggles and proper protective gloves). All reactions must be conducted inside the fume hood. The polymerization reactions should not be carried out with monomer concentrations more than $25 \%$ due to possible rapid and uncontrolled increase of temperature (runway reaction) [17].

\section{Results and Discussion}

Students were distributed into four groups to carry out the polymerization reactions with different starting concentration of acrylamide monomer (5, 10, 20 and 25 percent by weight). In most of calorimetric experiments, Styrofoam cups are used which are made from expandable polystyrene (EPS) filled with $\approx 98 \%$ air. In the current experiment, Styrofoam cups are not used as they can easily stick to the viscous polyacrylamide polymer and prevent the direct monitoring and observation of the reaction medium. Hence, the polymerization was carried out in transparent polystyrene double cup calorimeter to enable the direct observation of viscosity changes, water evaporation and gelation.

Enthalpy of polymerization was calculated assuming that (i) the calorimeter is perfectly insulated "adiabatic system"; (ii) conversion is complete; and (iii) the heat of polymerization, $\Delta \mathrm{H}_{\mathrm{p}}$, and heat capacity of the mixture are constant over the composition and temperature range expected.

Although PS transparent cups has 4-5 folds higher thermal conductivity compared to Styrofoam cups, we have selected not to determine the heat capacity of the polystyrene cup calorimeter as the obtained values for enthalpy of polymerization are comparable to the reported literature values, especially at monomer concentrations of 10-25 wt. \% (reaction reaches high conversions). Similar assumption to (i) has been used to approximate the heat capacity of human hand using Vienna sausage and coffee cup calorimeter setup [25]. It is worth mentioning that adiabatic calorimetry can be used not only for evaluation of reaction enthalpy, but also, for derivation of kinetic 
data such as activation energy from the temperature-time dependence relationship [26,27]. However, this is outside the scope of this experiment due to the simple and basic reaction setup used for conducting the experiment.

Redox initiated polymerization was employed to polymerize acrylamide at room temperature which allowed monitoring temperature changes to find out the enthalpy of polymerization. Compared to thermal imitation systems, redox initiation enables polymerizations at lower temperatures with higher molecular weight obtained polymers. Acrylamide can be polymerized at $50^{\circ} \mathrm{C}$ using APS as thermal initiator. However, when APS is used with TMEDA as a redox pair, the polymerization can be carried out at room temperature. TMEDA acts as a catalyst and lowers the activation energy for decomposition of APS by changing the reaction pathway [28], as illustrated in Figure 3.

The main observations for all groups are summarized in Table 3. Polymerization with 5 wt. \% AAM did not yield polyacrylamide as the obtained solutions did not exhibit any kind of viscosity. Hence, the polymerization conditions are not suitable for polymer formation. In comparison, polyacrylamide was formed from solutions with AAM content $\geq 10$ wt. \%. Gelation occurred with AAM contents $\geq 20$ wt. $\%$.
The results of the temperature change vs. time are listed in Table 3 and presented graphically in Figure 4. For all reactions, the starting initial temperature was $\approx 21^{\circ} \mathrm{C}$. The exothermic nature of the acrylamide addition polymerization is obvious and evident from the rapid rise in temperature profiles within 20 minutes reaction time. The reaction pathway can be divided into three distinct stages, which are:

\section{Stage 1: Induction period}

Addition polymerization is characterized by induction period which varies according to the type of initiator, initial temperature, presence of radical scavenger (e.g. oxygen) or other inhibitors. The same applies for redox pairs (APS + TMED). The rate of initiation depends on the concentration of the redox pairs and the initial reaction temperature [9]. Hence, variation in the initial temperature will affect the induction period with expected longer induction periods at lower initial temperatures. In the current experiment, all monomer solutions were brought to about the same temperature $\left(20.8 \pm 0.2^{\circ} \mathrm{C}\right)$ prior to the addition of redox initiators. As shown in Figure 4, all reactions exhibited similar induction period $\approx 3-6$ minutes. There is no significant change in the temperature during this stage, which means that this stage represents the initiation stage only.

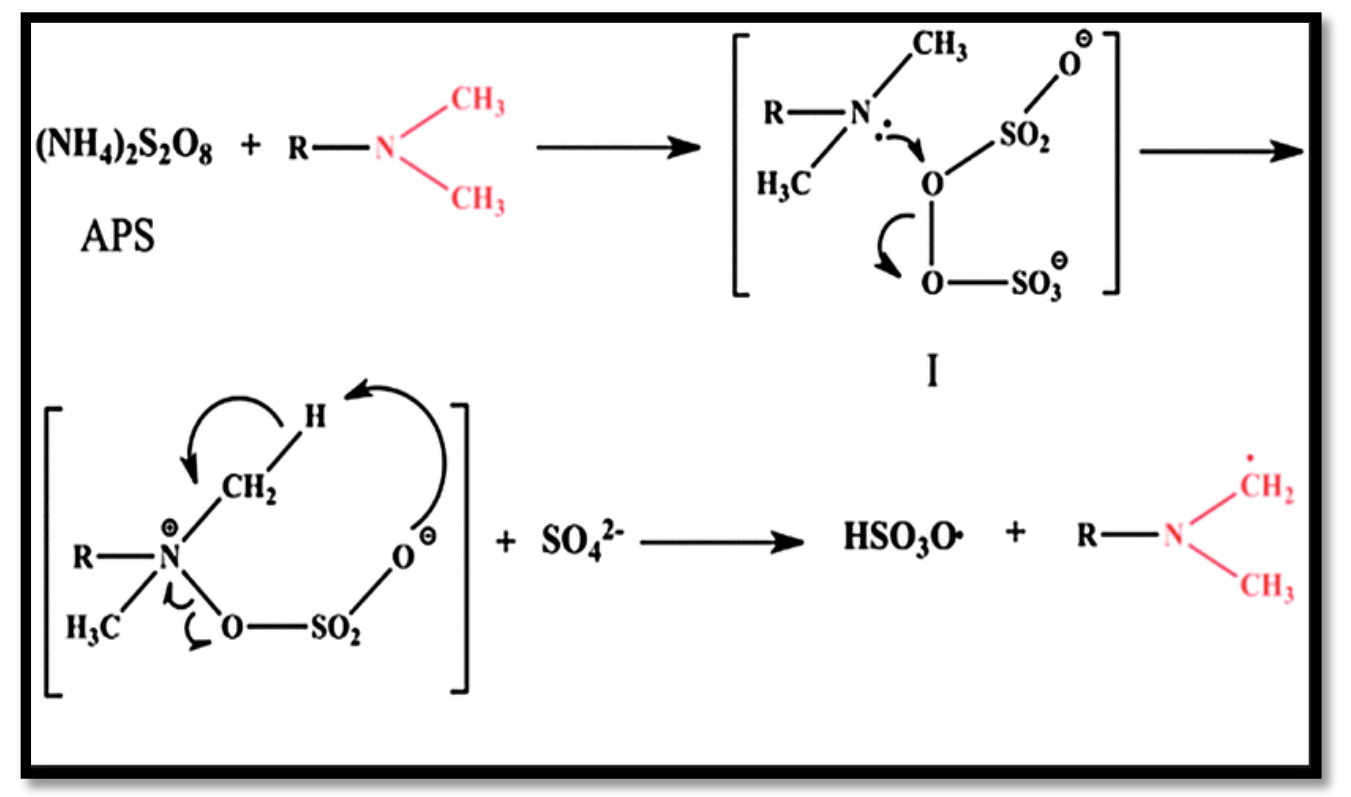

Figure 3. A schematic illustration for the decomposition of APS catalyzed by tertiary amines as catalyst; with permission from Ref. [28]. (c) 2016 Royal Society of Chemistry

Table 3. Observations and collected data for polymerization reactions

\begin{tabular}{|c|l|c|c|c|c|c|}
\hline $\begin{array}{c}\text { Acrylamide Content } \\
\text { (Wt. \%) }\end{array}$ & Viscosity Change & Gelation & $\begin{array}{c}\text { Water } \\
\text { Evaporation }\end{array}$ & $\begin{array}{c}\Delta \mathrm{T} \\
\left({ }^{\circ} \mathbf{C}\right)\end{array}$ & $\begin{array}{c}\mathrm{dT} / \mathrm{dt} \\
\left({ }^{\mathbf{}} \mathbf{C} / \mathbf{m i n}\right)\end{array}$ & Conclusions \\
\hline 5 & $\begin{array}{l}\text { No change } \\
\text { (Non-viscous). Stir bar movement did not } \\
\text { change }\end{array}$ & No & No & 8.9 & 1.7 & $\begin{array}{c}\text { No polymerization under } \\
\text { this conditions }\end{array}$ \\
\hline 10 & $\begin{array}{l}\text { Highly viscous solution. Stir bar movement } \\
\text { became too slow. Siphoning effect can be } \\
\text { demonstrated }\end{array}$ & No & No & 23.1 & 5.2 & $\begin{array}{c}\text { Suitable conditions for } \\
\text { polymerization }\end{array}$ \\
\hline 20 & $\begin{array}{l}\text { High viscosity, followed by gelation. Stir bar } \\
\text { stopped completely }\end{array}$ & Yes & No & 47.7 & 12.6 & $\begin{array}{c}\text { Gelled polymer. Difficult to } \\
\text { dissolve in water }\end{array}$ \\
\hline 25 & $\begin{array}{l}\text { High viscosity, followed by gelation. Stir bar } \\
\text { stopped completely }\end{array}$ & Yes & Yes & 74.2 & 31 & $\begin{array}{c}\text { Gelled polymer. Difficult to } \\
\text { dissolve in water }\end{array}$ \\
\hline
\end{tabular}




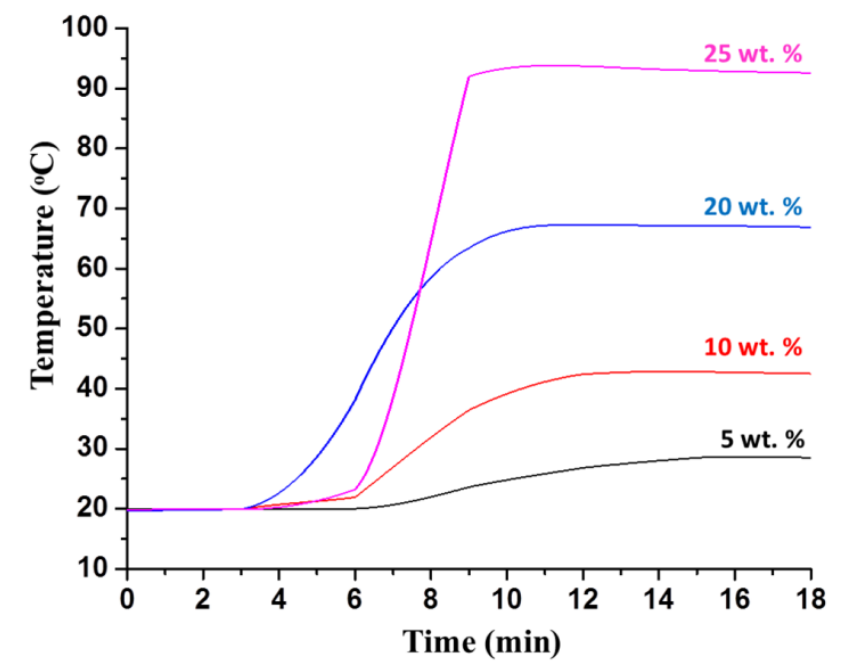

Figure 4. The change in temperature vs. time graphs for different monomer concentrations

\section{Stage 2: Auto-acceleration}

The auto-acceleration stage is characterized by sudden and sharp increase in the temperature [29]. The curve for the temperature vs. time is characterized by "S" shape. However, as the AAM concentration increases, the auto-acceleration effect become more pronounced and the "S" shape character become less evident, as in the case of the curve for 25 wt. \% AMM content.

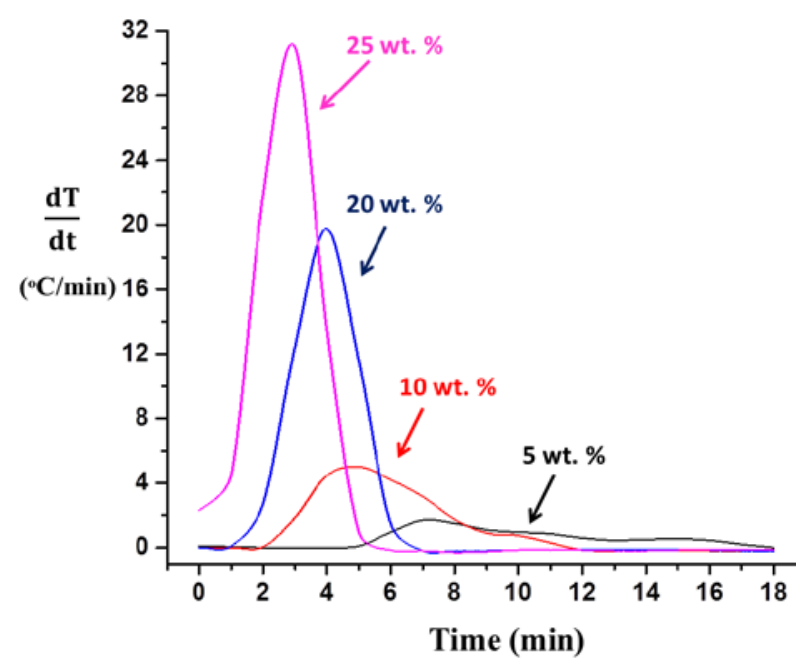

Figure 5. The rate of temperature increase for different polymerizations

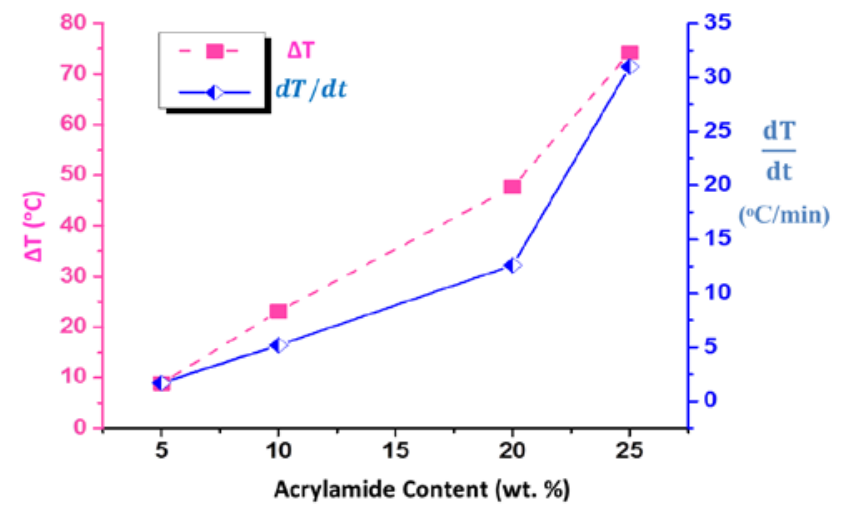

Figure 6. The non-linear relationship between monomer concentration, $\Delta \mathrm{T}$ and $(\mathrm{dT} / \mathrm{dt})$
The auto-accelerative nature of the addition polymerization can be traced from the presented plots of the first derivative (dT/dt), Figure 5. It can be inferred that the rate of temperature rise reached a maximum rate of $31^{\circ} \mathrm{C} / \mathrm{min}\left(\approx 0.5^{\circ} \mathrm{C} / \mathrm{s}\right)$, for solutions with 25 wt. $\%$ AAM content. Hence, it is very important to make sure that the cooling rate is greater than the rate of heat generation to avoid accidental thermal runaway situations. Gelation occurred during the auto-acceleration for highly concentrated solutions due to attained extreme high molecular weights.

From Figure 6, it can be inferred that the rise in temperature is linear up to 20 wt. \% AAM content, and then, it increases and deviates from the linearity. This could be attributed to the auto-accelerative nature of the addition polymerization in concentrated solutions/ pure monomers, where the kinetics changes due to increased viscosity, absence of mixing, reduced rates of termination and, consequently, higher propagation rates which yields high amounts of heat. The non-linear increase in the rate of temperature rise $(\mathrm{dT} / \mathrm{dt})$ is more pronounced from Figure 6 . The rate of temperature rise was almost tripled and increased from $12.6^{\circ} \mathrm{C} / \mathrm{min}$ to $31^{\circ} \mathrm{C} / \mathrm{min}$, when the concentration of AAM monomer was increased from 20 wt. \% to 25 wt. \%. Hence, the auto-acceleration effect is clearly demonstrated after certain concentration of monomer, or when reaching certain rate of temperature rise (e.g. $\left.\geq 0.5^{\circ} \mathrm{C} / \mathrm{s}\right)$. In addition, water evaporation was observed for the solutions with 25 wt. \% monomer concentration. Steaming and bubbling have been observed for polymerization of acrylamide with monomer concentration of 50 wt. \% [17].

\section{Stage 3: Post-Polymerization Stage}

This stage follows the auto-acceleration phenomena, where the maximum conversion and heat release have been attained. In the post-polymerization stage, the temperature starts to decrease slowly.

\subsection{Enthalpy of Polymerization}

Enthalpy of polymerization for all reactions was calculated using equations 3 and 4 . Results for $\Delta \mathrm{H}_{\mathrm{p}}(\mathrm{kcal} /$ mole) are summarized in Figure 7. Polymerization with 5 wt. \% AAM using the described conditions produced the lowest amount of heat with $\Delta \mathrm{H}_{\mathrm{p}}(14.10 \pm 0.54 \mathrm{kcal} /$ mole $)$. This could be attributed to incomplete conversion of AAM monomer as the obtained solutions were nonviscous. Hence, this result will not be considered and should be excluded. In comparison, the remaining three polymerizations produced heat in the range of $(\approx 16.5-19$ $\mathrm{kcal} /$ mole), which are comparable to the literature results $(\approx 17-20 \mathrm{kcal} /$ mole $)$. It can be inferred that the enthalpy of polymerization increased with increasing the concentration of monomer due to the following facts:

i. The reaction is exothermic, and hence, the amount of generated heat increases with increasing the mass/ moles of monomer.

ii. The amount of solvent was held constant $(100 \mathrm{~mL})$. Hence, cooling process provided by heat transfer to solvent decreases with increasing the monomer concentrations.

iii. The viscosity increased with increasing monomer concentration, as observed from the gelation of the 
AAM solutions with 20 and 25 wt.\% The increased viscosity will result in temperature gradient due to improper mixing (high viscosity) or absence of mixing (gel formation).

iv. The increased viscosity will decrease the rate of termination due to the formation of high molecular weight polymer (very long chains), which deactivate the segmental diffusion of the chains and it will hinder the termination by combination/coupling. In the same time, the rate of propagation will not be affected, and hence, the auto-acceleration effect will take place, resulting in high temperature raise.

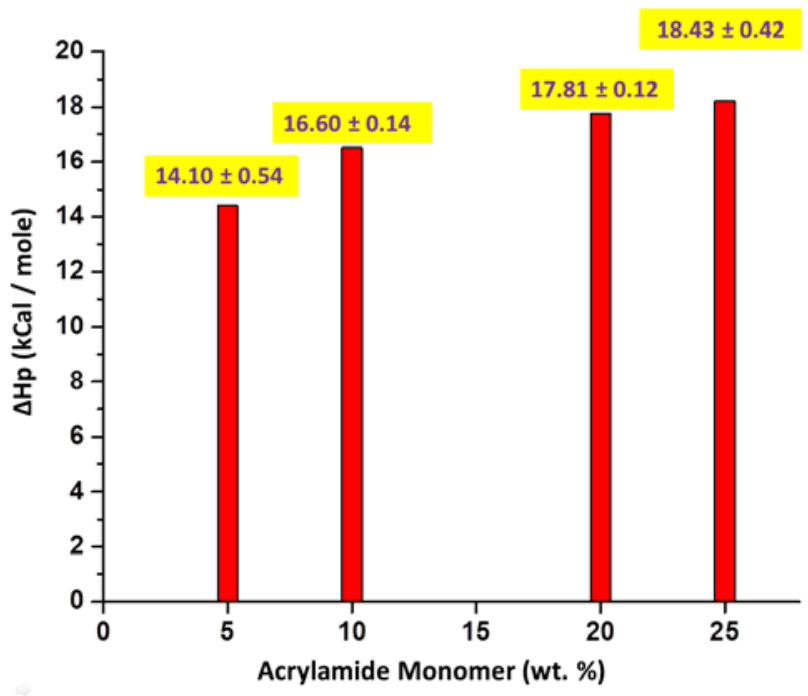

Figure 7. Enthalpy of polymerization for different polymerizations; the presented data are average of triplicates with reported standard deviation for the three runs

Based on the estimated enthalpy of polymerization, the maximum temperature of the reactor resulted from the polymerization reaction $(\Delta \mathrm{T})$ can be calculated. Also, based on estimated $\Delta \mathrm{H}_{\mathrm{p}}$, the scale-up for certain polymerization can be figured out and risk assessment analysis can be carried out.

\section{Example:}

A new process need to be scaled-up for polymerization of acrylamide using redox initiators APS and TEMDA. Based on your results from laboratory scale experiment for the determination of polymerization enthalpy, predict the maximum temperature that the reaction can reach. The following data are provided:

$\Delta \mathrm{H}_{\mathrm{p}}=-20000 \mathrm{cal} . / \mathrm{mole}$

Mass of water $=100 \mathrm{~kg}\left(5.6 \times 10^{3}\right.$ mole $)$

Mass of Acrylamide monomer $=355 \mathrm{~kg}\left(5 \times 10^{3}\right.$ mole $)$

Mass of redox initiators $=2.5 \mathrm{~kg}$

Total mass $=457.5 \mathrm{~kg}$

Heat capacity of the final mixture: $1.5 \mathrm{cal} . / \mathrm{g} /{ }^{\circ} \mathrm{C}$

Comment on the risk of carrying out the above polymerization.

Comment on the nature/ viscosity of the obtained polymer. Suggest possible solutions to control the polymerization process

\section{Solution:}

$\Delta \mathrm{H}_{\mathrm{p}}=(-20000 \mathrm{cal} . / \mathrm{mole}) \times\left(5 \times 10^{3}\right.$ mole $)=-\mathbf{1} \times 1 \mathbf{1 0}^{8}$ cal.

Note: The negative sign of $\Delta H_{p}$ means that the reaction is exothermic and releases an amount of heat/ energy equals to $1 \times 10^{8}$ cal.

Using equation 2 :

$\Delta \mathrm{T}=\left(\Delta \mathrm{H}_{\mathrm{p}} / \mathrm{m} \times \mathrm{S}\right)=\left(1 \times 10^{8} \mathrm{cal}.\right) /\left[\left(457.5 \times 10^{3} \mathrm{~g}\right) \times(1.5\right.$ cal. $\left.\left./ \mathrm{g} /{ }^{\circ} \mathrm{C}\right)\right]=146{ }^{\circ} \mathrm{C}$

This polymerization has a very high risk due to high amount of evolved heat in a short period of time (few minutes or less). Obviously, the final temperature of the reactor will be above $100^{\circ} \mathrm{C}$, which leads to boiling of water, expansion for the volume of solvent (water), generation of high pressure inside the reactor, and eventually causes a catastrophic explosion. Hence, even if there is a very effective cooling system, the cooling process will fail due to the high and sudden temperature rise inside the reactor, boiling of solvent and autoacceleration effect. In principle, $\Delta \mathrm{T}$ should be lower than the boiling point of solvent. In the case of water, $\Delta \mathrm{T}$ inside the reactor shall not exceed $90^{\circ} \mathrm{C}$ to prevent boiling of water.

Since the concentration of the monomer is high $\approx 78$ wt. \%, this polymerization will produce a gelled polymer. Simulating the whole reaction under isothermal conditions is necessary in small lab scale to verify the effectiveness of the cooling system. However, these conditions are not used in practical industrial setting due to auto-acceleration nature of alkene polymerization. The resulted gel polymer is expected to have a very low solubility in water. Possible solution is to decrease the monomer concentration (e.g. 15-20 wt. \%) and/or to lower the initial reaction temperature (e.g. $\left.0^{\circ} \mathrm{C}\right)$.

\section{Conclusions}

During this experiment, students gain and develop multiple practical skills related to polymer synthesis and understand many concepts related to addition polymerization including redox initiated polymerization, solution polymerization, exothermic reactions, enthalpy of polymerization, gel effect, auto-acceleration and runway reactions.

The enthalpy of exothermic polymerization of acrylamide was determined by simple and quick calorimetric technique. The performed adiabatic calorimetry is very useful for simulation of the worst case scenario in a small laboratory scale. The estimation of the maximum increased temperature $(\Delta T)$ helps to prevent failure of the cooling system and uncontrolled increase of temperature in the reactor.

The auto-acceleration nature of addition polymerization was traced during the experiment by increasing the concentration of AAM monomer. The gel effect was visualized by observing the increased solution viscosity until reaching a certain concentration that will cause polymer gelation.

\section{Acknowledgements}

The author acknowledges and appreciates Jubail Industrial College for providing the necessary lab facilities and chemicals inside the Chemical and Process Engineering Technology Department. 


\section{References}

[1] Hutley, T.J. and M. Ouederni, Polyolefins-The History and Economic Impact, in Polyolefin Compounds and materials. 2016, Springer. p. 13-50.

[2] Odian, G., Principles of polymerization. 2004: John Wiley \& Sons.

[3] Roberts, D.E., Heats of Polymerization. A Summary of Published Values and Their Relation to Structure. Journal of Research of the National Bureau of Standards, 1950. 44: p. 221-32.

[4] Norrish, R. and E. Brookman, The Mechanism of Polymerization Reactions. I. The Polymerization of Styrene and Methyl Methacrylate. Proceedings of the Royal Society of London. Series A, Mathematical and Physical Sciences, 1939: p. 147-171.

[5] Norrish, R. and R. Smith, Catalyzed polymerization of methyl methacrylate in the liquid phase. Nature, 1942. 150(3803): p. 336-337.

[6] Trommsdorff, V.E., H. Köhle, and P. Lagally, Zur polymerisation des methacrylsäuremethylesters1. Macromolecular Chemistry and Physics, 1948. 1(3): p. 169-198.

[7] Ozaki, T., et al., The roles of the Trommsdorff-Norrish effect in phase separation of binary polymer mixtures induced by photopolymerization. Polymer, 2014. 55(7): p. 1809-1816.

[8] O'neil, G.A., M.B. Wisnudel, and J.M. Torkelson, Gel effect in free radical polymerization: model discrimination of its cause. AIChE journal, 1998. 44(5): p. 1226-1231.

[9] Sepulveda, P. and J. Binner, Persulfate- Amine Initiation Systems for Gelcasting of Ceramic Foams. Chemistry of materials, 2001. 13(11): p. 4065-4070

[10] Young, A.C., et al., Gelcasting of alumina. Journal of the American Ceramic Society, 1991. 74(3): p. 612-618.

[11] Owolabi, R., M. Usman, and A. Kehinde, PROCESS SAFETY IN THE RADICAL POLYMERIZATION OF STYRENE: FROM BULK TO SOLUTION/EMULSION PROCESS.

[12] Clark, W., et al., An Experiment to Illustrate the Hazards of Exothermic Reaction Scale-Up. Chemical Engineering Education, 2017. 51(1): p. 35-40.

[13] Charter, C.I.R., SAFETY ISSUES IN THE SCALE-UP OF CHEMICAL REACTIONS. 2013.

[14] Kao, C.-S. and K.-H. Hu, Acrylic reactor runaway and explosion accident analysis. Journal of Loss Prevention in the Process Industries, 2002. 15(3): p. 213-222.

[15] Gustin, J. and F. Laganier. Understanding vinyl acetate polymerization accidents. in INSTITUTION OF CHEMICAL ENGINEERS SYMPOSIUM SERIES. 1999: HEMSPHERE PUBLISHING CORPORATION.

[16] Gustin, J.-L., Understanding vinyl acetate polymerization accidents. Chemical Health and Safety, 2005. 12(6): p. 36-46.

[17] Silversmith, E.F., Free-radical polymerization of acrylamide. J. Chem. Educ, 1992. 69(9): p. 763.

[18] Ohshima, I., et al., Polymerization of acrylamide in the presence of water-soluble nitrogen compounds. 1976, Google Patents.

[19] Kishore, K. and K. Santhanalakshmi, Thermal polymerization of acrylamide by differential scanning calorimetry. Journal of Polymer Science: Polymer Chemistry Edition, 1981. 19(10): p. 2367-2375

[20] Rodriguez, F., et al., Principles of polymer systems. 2014: CRC Press.

[21] Goren, M.B., Polymerization of acrylamide monomer in the presence of free ammonia and the resulting polyacrylamide product. 1965, Google Patents.

[22] Benedict, G.D., High molecular weight acrylamide polymer production by high solids solution polymerization. 1975, Google Patents.

[23] Tareke, E., et al., Analysis of acrylamide, a carcinogen formed in heated foodstuffs. Journal of agricultural and food chemistry, 2002. 50(17): p. 4998-5006.

[24] Mottram, D.S., B.L. Wedzicha, and A.T. Dodson, Food chemistry: Acrylamide is formed in the Maillard reaction. Nature, 2002. 419(6906): p. 448-449.

[25] Vannatta, M.W., M. Richards-Babb, and R.J. Sweeney, Thermochemistry to the Rescue: A Novel Calorimetry Experiment for General Chemistry. Journal of chemical education, 2010. 87(11): p. 1222-1224.

[26] Gordon, M., Reaction kinetics of adiabatic systems. Transactions of the Faraday Society, 1948. 44: p. 196-202.

[27] Dammers, W., W. Frankvoort, and M. Tels, Temperature-time and temperature-concentration curves in reaction calorimetry. Thermochimica Acta, 1971. 3(2): p. 133-142.

[28] Zhang, S., et al., Revisiting the mechanism of redoxpolymerization to build the hydrogel with excellent properties using a novel initiator. Soft matter, 2016. 12(9): p. 2575-2582.

[29] Abu-Thabit, N.Y., Chemical Oxidative Polymerization of Polyaniline: A Practical Approach for Preparation of Smart Conductive Textiles. Journal of chemical education, 2016. 93(9): p. 1606-1611. 